\title{
Cognition as a Transformative Process
}

Re-affirming a Classical Pragmatist Understanding

Vera Saller and Donata Schoeller

\section{(2) OpenEdition \\ Journals}

Electronic version

URL: http://journals.openedition.org/ejpap/1211

DOI: 10.4000/ejpap. 1211

ISSN: 2036-4091

Publisher

Associazione Pragma

\section{Electronic reference}

Vera Saller and Donata Schoeller, "Cognition as a Transformative Process », European Journal of Pragmatism and American Philosophy [Online], X-1 | 2018, Online since 20 July 2018, connection on 01 May 2019. URL : http://journals.openedition.org/ejpap/1211 ; DOI : 10.4000/ejpap.1211

This text was automatically generated on 1 May 2019.

\section{(c) $($ ) $\odot$ (8)}

Author retains copyright and grants the European Journal of Pragmatism and American Philosophy right of first publication with the work simultaneously licensed under a Creative Commons AttributionNonCommercial-NoDerivatives 4.0 International License. 


\title{
Cognition as a Transformative Process
}

\author{
Re-affirming a Classical Pragmatist Understanding
}

Vera Saller and Donata Schoeller

1 We begin with brief remarks on the debate on non-conceptuality. We show that certain aspects of a pragmatist approach have found its ways into today's discussions. However, the underlying understanding of knowledge based on the justification of beliefs has stayed untouched in this discussion, and the classical pragmatist approach has not been considered. Dealing with the question whether a qualitative dimension in cognition is a relapse in givenism, we argue that this is not the case when taking the implications of knowledge as transformational process seriously. Re-introducing the perspectives of Peirce, Dewey and Gendlin we show how an interactive fine-grained description of knowledge as a transformative process explicates the pragmatist concern of cognition as a fundamental prerequisite to meet the challenges of human life. By conceiving knowledge as a transformative and interactional process, one acknowledges at the same time the dimension of "firstness" in experience. Our paper aims to show that this acknowledgment does not imply falling back into the Myth of the Given.

\section{Pragmatist Shifts in the Debate on Non-Conceptual Contents of Knowledge}

2 In his early book Mind and World (1994), John McDowell insists on the conceptuality of non-conceptual content drawing powerfully on Kantian perspectives. According to him, a deeper dualism behind the relation of the conceptual and intuitive components of knowledge has to be acknowledged: the Kantian problem of how to relate reason's spontaneity to a receptivity grounded in the natural realm of law. McDowell's response to this challenge is to lay out a bigger picture of human development, including the fact that human beings are born into a language that "serves as a repository of tradition, a store of historically accumulated wisdom about what is a reason for what" (McDowell 1994: 126). 
His suggestion to integrate "Bildung" into the natural development of human beings seems to arrive where classical pragmatists begin.

3 On a more detailed level of argument, however, McDowell demonstrates concepts in use even when there seems to be no identifiable concept available for what is experienced. Responding to Gareth Evans' (1982) argument that humans often find themselves confronted with aspects of the world they do not have any concepts for, for instance a certain shade of color, McDowell points out that, even in this case, one can nevertheless refer to "that shade of color." The capacity for recognition is another strand of evidence McDowell presents for every moment of perceptual intake being conceptual, thus claiming that the capacity for recognition calls for conceptual memory (1994: 46).

Christopher Peacocke famously argued against these suggestions with what is now called "The Fineness of Grain" argument. By taking account of phenomenological aspects of experience that exceed the conceptual repertoire (cf. Peacocke 2001), Peacocke indicates how perceptually based discrimination of properties and experience of moments are so replete with content that goes beyond memory and identification (ibid.: 251). He argues every detail of the lived situation cannot be remembered but even if memory were as finely discriminative as perception, the recognition argument would not hold when perceiving properties for the first time. Peacocke's insistence on perceptual quality also implies that "the content of perception is more fine-grained than the content of propositional attitudes" (Bermúdez \& Cahen 2012).

5 Suggesting that non-conceptuality is distinct from conceptuality in "making it available," Peacocke (2001: 244) seems to envision non-conceptuality as a kind of active base for concepts, thus coming closer to the phenomenological perspectives emphasized by classic pragmatist thinkers (as we will show below). McDowell himself will have shifted his position in the years to come. By dropping the assumption of experience as mere actualizations of conceptual capacities, his claims draw more closely on Kant's notion of intuition, understanding rational capacities to permeate our experiences, even those "we act on unreflectively in our ordinary coping with our surroundings" (McDowell 2008: 13).

Further steps in a pragmatist direction have been explicitly or inexplicitly taken by more recent contributions to the debate. Robert Hanna's lucid overview on the debate provides strong interventions for the non-conceptualist side, also by drawing heavily on Kant. Yet, juxtaposing the "Grip of the Given" to the famous "Myth of the Given," Hanna introduces perspectives of continuity that clearly exceed the Kantian positions, while also reformulating non-conceptual content as "situated content." By considering whole situations, the perspective on non-conceptual content is widened beyond the mere perceptual intake. He also includes evolutionary perspectives in our understanding of cognition and reminds us not to forget a

[...] continuous thread-of-life by which the world is sensorimotor-subjectively or pre-reflectively consciously delivered up from human animal experience to our self-conscious or self-reflective thought and action-oriented deliberation. (Hanna 2011: 390)

7 The "grip of the given" as embodied, contextualized living provides the basis from which deliberate thinking arises (ibid.). Continuity, as suggested by Hanna, has to be considered in mutual transformative, rather than in exclusive relations between what is conceived as conceptual and non-conceptual contents, as well as between non-human and human aspects of experience. 
In a careful analysis of the debate between McDowell and Hubert Dreyfus, Dan Zahavi (2013) seems to complement Hanna's line of argument, by pointing to the unsurmountable discontinuity between animal and children on the one hand, and rational, lingual beings on the other, which seems implied in McDowell's position (cf. also, Welchman 2008; Godfrey-Smith 2010: 317). However, both authors, according to Zahavi, share a concept of mindedness that does not account for the character of "prereflective selfconsciousness" resp. "for-me-ness of experience."

9 A similar direction is taken up in Steven Levine's (2012) critical discussion of Robert Brandom's "rationalist pragmatism" (Brandom 2011: 32). Levine carefully lays out some side effects of Brandom's position and demonstrates how it re-affirms a subtle, yet decisive separation between rational capacities and bodily responses. Drawing explicitly on John Dewey to point to the developmental character of rational capacities, Levine suggests ways to overcome the kind of rupture he detects in Brandom's thinking. By considering rational behaviors as an acquired capacity "that develop in time due to a series of overlapping processes" (Levine 2012: 16), the divide between articulated reasons for action and the responding body closes. A similar emphasis on development in regards to conceptual schemes as well as language can be found in Jennifer Welchman's article (2008) on Dewey and McDowell.

\section{Knowledge As Transformational Practice}

Before moving on to a classical pragmatist understanding of cognition, which, as we would like to suggest, is first and foremost, to be characterized as a transformative process, it seems worthwhile to note a common denominator on which the abovementioned arguments seem to operate. This consists in the internalized critique of what Wilfrid Sellars famously termed the "Myth of the Given" (2000/1956). With "given," Sellars depicts an epistemological blindspot in which observations as states of knowing are given as an empirical description, instead of being understood as elements in the logical space of reasons, in which one is justifying and able to justify what one says.

11 Knowledge implied by the Myth, as McDowell summarizes, is "entitlement to judge that things are thus and so because experience reveals things are thus and so: for instance, seeing that something is thus and so" (2008: 2). Nothing immediately "given," as we convincingly learn from the critics of the "Myth," can act as a guarantee that judgements or beliefs about things being in one way or another are true. The wrongness of the Myth of the Given is widely discussed in regards to its wrongly held foundational functions concerning the possibility of justified knowledge and in making sentences and theories true. Donald Davidson summarizes this as a mistake in category: "no thing makes sentences and theories true." (Davidson 1974: 194; original emphasis).

12 However, with a few exceptions, this kind of critique and its many variations leave the concept of knowledge as justified beliefs untouched or unquestioned. True or at least verifiable propositions of things being "such and so" seem to remain the accepted basis on which different strategies of criticism of the misconception of the "given" set forth.

13 In the following, we do not lay out yet another strategy responding to the threat of the Myth. Rather, we want to emphasize aspects of cognition which are blind spots in this kind of approach to knowledge, centering chiefly on justification of beliefs. 
By bringing the classical pragmatists into the discussion, we would like to shift this perspective on knowledge by emphasizing its development and its fundamental usefulness for the human species. We will say more clearly in which way the respective pragmatist approach introduces a transformational approach to epistemology, and how this radically challenges a foundational understanding of knowledge, with its polarity of either assuming something 'given' that justifies beliefs, or the threat of skepticism.

Re-affirming a classical pragmatist stance will also remind us that justifiable claims are results of manifold practices transforming situational complexity into useful beliefs within a space of reason. Classical pragmatists have demonstrated that these processes need to be closely considered in order to understand a transformational and processual character of cognition.

We have to ask ourselves however, whether by referring to "qualitative experiences" of situations and "Firstness" of impressions in the Deweyan and Peircean sense, for example, we slide back into givenness as Colin Koopman suggests (2009: 76). In emphasizing practice as the main element of his understanding of Pragmatism's theory of knowledge he stresses transitionality as a main feature of cognition, emphasizing the historical and temporal change process of all knowledge (Koopman 2009). We appreciate his emphasis on practice, yet Koopman avoids the qualitative dimension of experience, out of fear to fall back into the "Myth." Disregarding the qualitative dimension of real situations in which knowledge makes transisitions neglects to take account of the noncontingent character of the transitional movement he highlights. To keep it safe from any danger of givenism, the word practice in his approach thus gains an important role while at the same time hardly obtaining any detailed description or attention. Koopman writes:

[...] the transitionalist's account also has no need for referring to experience and language as supplying the basis upon which practice is elaborated. Practice is elaborated only upon itself, that is, upon its own accumulated historical furnishings. It confronts only with ongoing stream of practice in its further construction and reconstructions of itself. (Koopman 2009: 118)

The problem of the Myth of the Given, from this vantage point, dissolves, but so do people and the real experienced challenges of daily situations, which are met by knowledge that makes a difference. Practice seems to need nothing but more practice, stripped of predicaments of contexts, challenges, problems, as well as dangers and opportunities that arise through the way they are handled and formulated.

In contrast to Koopman's resistance towards an experiential embededness of practice, the initial pragmatist move consists in tying together rational cognition and situational specificity, as the founding father Dewey quotes William James:

The effective meaning of any philosophic proposition can always be brought down to some particular consequence, in our future practical experience, whether active or passive; the point lying rather in the fact that the experience must be particular, than in the fact that it must be active. (Dewey's Italics) (Dewey 1916: 710-1/James 1904: 674)

Dewey introduces the term "situation" along the lines of qualitative and complex experiences, which allow close up studies of cognition as a subtle and intricate interaction. In comparison to these fine-grained perspectives, Koopman's reference to practice seems rather abstract. In contrast, also Peircean "Firstness," which he criticizes as falling for giveness, is a processual moment of cognition, itself a product of interpretative processes and evolving systems of interconnected signs. A dynamic emergence of a world in need of conceptual forms for clarification also implies the 
development of a space of reasons. The space of reasons thus becomes one dynamic aspect of a wider and intricate evolving system of inter-related meanings involved in knowledge.

Also for Dewey, neither language nor experience can be focused on in isolation, but always in relation to the continuity of body-environment interactions responding to continuous needs.

The same applies to Eugene Gendlin's epistemological approaches and his philosophy of language. His embodied, interactional understanding of the development of knowledge is based on his rigorous close-up studies of meaning making processes, which is why we call him a Classical Pragmatist of the third generation.

With Gendlin, the Classical Pragmatist approach to practice becomes even more finegrained. His methods of Focusing and Thinking-at-the-Edge draw on tacit dimensions of knowledge, the "authority" of which is not "given," but in need of constant, sometimes very subtle practices, such as a slight shift in awareness or attitude. Next to interpretative process, Gendlin demonstrates how slight differences in attending to a felt dimension of experience can make an important difference in practice. Taking into account vague beginnings to evolve into fruitful cognitive processes and to be transformed into (more) stable and explicit forms of knowing, knowledge as a transformational process implies practices cultivating situational experiences on different fine-grained levels. This is the recurrent theme that motivates the choice of our three classical pragmatist thinkers.

\section{Peirce's First and Habits}

3 It was Joseph Ransdell (1979) who showed that regarding perception, Charles S. Peirce had overcome the traditional alternative between the skylla of naive realism and the charybdis of skepticism more than a hundred years ago. The pragmatistic turn, initiated by Peirce, succeeded in this by combining the customarily conflicting doctrine of representative content on the one hand and immediate perception on the other. This was possible because he differentiated the immediate sense impact, which he named "percept" from perception (or perceptual judgement) and introduced the abductive inference. The "percept" as raw sense impression in its Firstness is left in total potentiality (indeterminacy), whereas thoughts as Thirdness have become conceptual and conventional.

24 One could argue that the gap between iconic Firstness and conceptualized Thirdness corresponds to the dichotomy alluded to in the contemporary debate. But Peirce's account shifts the picture because 1) he considers perception as one dynamic instant in the more encompassing process of thinking and acting, 2) the consideration of thought as sign process on different levels overcomes the polarization of dichotomies, and 3) his theory of abduction opens up a spectrum of cognitive movements shedding a new light on whether these processes are to be considered as rational or pre-rational.

Peirce conceived of thinking as a process of sign-interpretation through and through. In other words, he showed that there is no state, which is not a sign-process, even if this may be considered as pre-reflective. By demonstrating that thinking is not possible without signs, he found different ways to conceive how pre-conceptual states do not have to be discursive and are still permeated by rational capacities without underestimating their difference to propositional content, yet without introducing a rupture either. Instead of re-emphazising the two classical components of knowledge, his radical 
thinking of signs opened up ways to reflect thought and knowledge as a continuous process reaching from preconceptual states to propositional statements, always moving and finding new formulations and meaning:

From the proposition that every thought is a sign, it follows that every thought must address itself to some other, must determine some other, since that is the essence of a sign. (CP 5.253)

His consideration of these processes is intrinsically interwoven with his categories. We already mentioned McDowell's argument for conceptuality in sensations, where he shifts from an iconically lived instant to an indexically meant "this shade." Distinguishing the iconically experienced sense from the indexically experienced shade of color, indicates two different aspects of a process, aspects that cannot substitute each other, but that build and transform each other. The indexical this points to a certain trait of reality, to this shade of color. The indexical aspect is second to the iconically lived moment, it is the next step of becoming aware of a thing in the interpretative process. It is the second level, the level before we are able to tag something with a name - which would be the level of the Third. The reference to indexical experience does not refute non-conceptual content however. In trying to understand perception, it is not only the registering of things that attract our attention that matters. Peirce's iconicity allows us to take into account that our orientation in the world includes many things that we perceive without them being the focus of our attention. A major part of being able to act in the world and in situations happens, as Peirce rightly points out, with only peripheral awareness. This is especially true of bodily sense of somatic consciousness, like balance, temperature and quality of air. For example, we are habitually capable of adapting to the temperature of a room, by opening and closing windows and doors and by adding another piece of clothing, or taking it off. Until a person begins to feel uncomfortable, one does not pay any focal attention to the definable temperature of the surroundings.

Although Peirce rather seldom refers to bodily feelings as such his notion of iconicity and indexicality implies a bodily situation in every further sign process. This enriches today's debates, which often claim the importance of including the prereflective embodied experience of situations. The Peircean notion of habit plays a noteworthy role in this respect. Hubert L. Dreyfus (2013) describes moments of absorption in sportive activities and habitual orientation as entirely without participation of consciousness and nearly automatized. Zahavi (2013) rightly criticizes these descriptions for denying the phenomenological important aspects of pre-reflective self-consciousness and "for-meness of experience." Here, the categories of First and Third could become germanely useful in precise ways. Habitual bodily actions and absorbed states are not guided by selfconscious understanding; nevertheless, they are mindful and sociable. This does not mean that they are conceptual, because we understand deliberation as developing in levels, as an ever-growing net of relations of interconnected signs. The finely woven web of signs includes images, sounds and smells as well as clearly differentiated concepts. "For-me-ness experience" certainly happens on a more indexical or iconical level.

The capacity to react reasonably on a bodily level of learned habits is the subject of Levine's (2012) criticism of Brandom. Although he neither mentions Peirce nor benefits from the possibilities afforded by his sign-theory, he "re-discovers" the importance of habits.

But while passive, habits and bodily skills nonetheless have a rational intelligibility or significance that is determined by the intelligibility of the projects of which they are a part. When this intelligibility is disrupted because our habits and bodily skills 
can no longer unreflectively cope with the situation into which they have been drawn, the active capacities for deliberation and practical reasoning emerge. (Levine 2012: 13)

At the end of his article, Levine mentions Dewey, but not Peirce. Nevertheless, he shows a way to defend classical pragmatists, especially Peirce, providing ways to think beyond the Myth. Levine writes:

If we stick to the practical case, we can avoid this conception [the Myth] by recognizing that the capacities that make action possible - i.e., the ability to reason practically and to act on bodily habits - are acquired capacities that are relatively plastic, i.e., are one's [sic!] that develop over time. (Levine 2012: 14; original emphasis)

This suggests that current discussions end at the point where Peirce's fundamental dictum "all thought is in signs" (CP 5.253) indicates a path. More inclusion of Peircean thought promises to bring further fruitful inspirations to these debates. We will continue unfolding just a couple of these.

31 The gap between First and Third is completed by the Second, the indexical contact with reality, which ignites the mental activity of abduction. This intrinsically entails the possibility of error. To admit that humans are, in fact, capable of "taking hold of aspects of world" (McDowell 1994: 58) while simultaneously bearing in mind possible misrepresentation, is a major feature in Peirce's categorical thinking. Accounting for the embodied ways of contact with the world without taking this to be any kind of authority for the interpretation of things being "such and so," is the important lesson today's discourse can learn from Peirce. It was his way of responding to the classical threat of skepticism. The possibility of failure initiated philosophers' refusal of naive realism and drew them in the direction of radical skepticism.

Especially in the time of Peirce, new evidence of the weakness of our sensory organs and bistable pictures, like Schröder's staircase and Joseph Jastrow's duck/rabbit were a matter of public interest. Like Ludwig Wittgenstein, Peirce showed particular interest in these cognitive puzzles. ${ }^{1}$

With the category of the Second, one seems to touch the ontological level. If we suggest that Peirce considered the Second as the moment when we encounter reality, many may ask: what reality? Peirce was a skeptic in the sense that he acknowledged the necessary impact of cultural meanings which form our perception and imply the danger of perceptive deformation, as well as the obvious possibility of false interpretation. Nevertheless, he always allowed for the reality of a mind-independent world, as well as the clash with this kind of pre-conceptual reality. It is this reality and its challenge, which he took to be the ultimate target of science. ${ }^{2}$ Compared with contemporary and postmodern authors, one of the most surprising facts in Peircean philosophy is this tension: although he insists that we do not have direct access to the world without the mediation of signs, he nonetheless stresses what can be called the phenomenological aspect of experience that exceeds a conceptual grip. This is most apparent in the aspect of iconicity. Iconicity as the most basic sign-level takes experience to be a sign for further experience. One relates to the world's properties, in which one is embedded, not only with concepts but also with embodied needs and primary dependency towards others.

According to Peirce, these needs and dependencies are expressing themselves within a net of interconnected signs, on the pre-conceptual level as icons and indexes (First and Second), slowly developing into conceptual meanings (Third). However, we must 
remember that the development of meaning is a process of continuous learning. Peirce's iconic level is a powerful tool to include these primary bonds as agencies of learning. On this iconic level no sharp distinctions are to be drawn since icons are not signs for different things, but lay the ground for a potential interpretation. Because a smell reminds us of another or "looking at the one is like looking at the other in some respects. [...] It is the base on which all other forms of representation are built." (Deacon 1997: 76f.). In this way signs, experience and world cannot be separated (cf. Jung 2009; 2013).

Compared to the dual pattern, which permeates debates on the Myth and on conceptuality versus non-conceptuality, Peirce's approach unfolds the multifaceted structure of conceptuality, based on three levels, similarity (icon), contiguity (index) and conventionality (symbol). In today's discourse, it is Hanna (2011) who expresses the need for understanding the process of knowledge developing in levels (cf. also Schlicht 2008). As already mentioned, his approach is based on an unconventional analysis of Kant, regrettably without mentioning Peirce. Peirce allows us to think, that before explicit conceptual interpretation even starts, we have the capability to "liken" 3 traits of reality. On this "first" level, perception functions iconically. The shapes that we perceive in the first sensory impression are not deliberately classified yet. Following the Peircean categories, it is very clear that the signs on the level of First elicit the responsive capability to assimilate properties of things. It is the human senses that are assigned to "liken" properties with their grasp, be this fingers, ears, skin, nose, tongue or eyes. It is again Ransdell (1979) who reminds us that this principle of iconicity is originally an Aristotelian idea. ${ }^{4}$ Nevertheless, it seems completely forgotten in contemporary discussions.

The potentiality of the unformulated percept on the level of First reminds us of something further. Insofar it is not conceptualized or at least understood as indicating something (as indexical pointing does), the percept is not a distinct intake. This is important to answer the question whether Peirce would agree with the idea of nonconceptual content. As the content of iconic signs is not conceptualized, couldn't we call it non-conceptual? The question is, if iconic resemblances already mean "content," or just a germ of a developing sign - more accurately - having the potential to develop. For this question we have to keep in mind that there are no purely iconical signs, in other words, there is no strict separation of the categories since every sign is constituted by the interrelation of all three levels. Also, the sensual intake does not have any meaning per se, in isolation.

37 It is intrinsically relational to memories or images of past experience and to pressing needs of the body, in this way it has the capacity to become meaningful in several transformational steps or shifts.

In developmental psychological descriptions of how newborns experience the world, the phenomenological and developmental character of the First gathered evidence. Daniel Stern (1985) summarizes the rich material of experiments and observations, presenting the "interactional world of babies" in an empathic way to the reader. A most surprising result from a series of experiments was the fact that babies have cross-sensual capacities (e.g. rhythms, visual images or sounds) already shortly after birth. They recognize their mother by her face, as well as by her scent or the way she walks, breathes or talks. In a similar way, the new field of neuro-phenomenology emphasizes the capacity of the mature human mind to transformatively interrelate a variety of sensual inputs on the fringes of awareness: 
The analysis of the descriptions we have gathered, demonstrates that the vocabulary used to describe the "stuff of felt meanings" often simultaneously calls on several sensorial registers: the visual (shape, shadow, fuzzy etc.), the kinetic, and the tactile (vibration, pulsation, pressure, density, weight, texture, temperature etc.), the auditory (echo, resonance, rhythm etc.) and even the olfactory or the gustative. (Petitmengin 2007: 63)

Only if one fails to account for the first person aspect of growth and development of meaning, can one regard such experiential process, as Koopman does, as a danger of falling back into givenism (2009: 122).

\section{Dewey's Situation and Interaction}

This is why it seems promising to us, to also take a close look at John Dewey again. He introduces qualitative aspects of experience into the epistemological debate of his time in a rather bold manner, stressing their vital functions for cognition. Throughout, these passages convey an understanding of cognition that is highly dynamic and that is the result of the transformation of any experiential material it emerges from. What is 'given' is never a foundational basis of knowledge, but an initial phase, changing rapidly like a 'storm' in ways that only allow us to speak of a stable product at the end of a process. This processual and transformative account undermines any givenist understanding of knowledge because it leaves behind the assumption that knowledge of something being 'such and so' is founded on non-conceptual perception.

of course, the differences between Dewey's and Peirce's approach to knowledge need to be closely studied and are subject matter of worthwhile research (cf. for example Dewey 1916; Tschaepe 2013: 39, FN 3). For our purpose here, we want to concentrate on the continuity of the classical pragmatist understanding of knowledge, knowledge understood as ever changing with evolving results of interpretative processes that are grounded in the daily challenge of action and problem-solving. The non-contingency of this process does not only rely on logical structures and measurements, but on the embodied and lived experience of situations and their needs. This is the classical pragmatist frame in which to understand intellectual operations.

Taking seriously daily situations, their predicaments and requirements leads beyond the binary constellation of conceptual and pre-conceptual which pervades today's debates.

Similar to Ludwig Wittgenstein, Dewey introduces a philosophically uncommon starting point of epistemological reflection by reminding philosophers, past and present, of the simple fact that thinking and speaking begin in situations (1930) and not with singular perceptions (such as shades of colors, etc.). From this vantage point, the level of abstraction of today's debates becomes apparent: discussing experience or knowledge on the grounds of isolated propositions within the frame of the duality of conceptual vs. non-conceptual content, distinctions derived from the history of philosophy, not from the predicaments of daily life.

Dewey, however, reminds us:

In actual experience, there is never any such isolated singular object or event; an object or event is always a special part, phase, or aspect of an environing experienced world - a situation. (Dewey 1938: 66)

Yet, one may legitimately ask: how are situations experienced if not by perceiving and conceptualizing? It is to this kind of question, that Dewey gives a new variety of answers. 
Thinking about experience based on the traditional epistemological split between concepts and perception omits to take into account how living in situations "functions" in the way we perceive and conceptualize things. Experiencing a situation, for instance, functions in ways that participants "know" what is relevant to say and distinguish, what needs no mentioning, what needs emphasis, etc. From "here" different kinds of epistemological questions arise, that Gendlin, as we will show later on, develops further. For instance, how is it that researchers do not have to choose between thousands of percepts or thousands of concepts what is relevant to "know" and to say? Dewey points to a contextual, environmental, social, as well as a historically-situated starting point of epistemological reflection encompassing every single cognitive operation while being changed at the same time. Dewey's critical attitude towards epistemological analysis is the logical result of this view, making us aware that analysis itself is a change-process: conditions of cognitions found in this process are a result of a reflective transformation of what is reflected upon. The actual stages of this dynamic thinking process do not show up anymore in the clear structure that is presented as 'found.' W. Teed Rockwell re-affirms Dewey's point about analysis' crucial limitations, stressing that "below a certain level of analysis, that which is realest to us, lived experience, [...] inevitably get(s) bypassed" (Rockwell 2005: 141). Once lost out of sight in the textbooks of philosophy and science, it is difficult to bring back. McDowell, from another, more skeptical stance, acknowledges the problem: if thought and judgment is to be recognizable as bearing on reality, there must be external constraint that is unlike an analyzed perception of concept, or else thinking and speaking would be equivalent to "frictionless spinning in a void" (1994: 11). Questions about how judgments are controlled by something outside of judgment again lead directly to the problems involved in the Myth. McDowell suggests that by understanding conceptual capacities taking part in receptivity (1994, Lecture 1), this problem is overcome. Classical pragmatism goes further in opening up the bigger picture and shifting a basic epistemological approach. Dewey directly criticizes a skeptical split in our approach to the world:

It is only when an object of focal observation is regarded as an object of knowledge in isolation that there arises the notion that there are two kinds of knowledge, and two kinds of objects of knowledge, so opposed to each other that philosophy must either choose which is 'real' or find some way of reconciling their respective 'realities.' (Dewey 1938: 67)

In order to overcome inquiring into objects of knowledge in isolation, Dewey's descriptions at this point seem to shift into phenomenological accounts of how it is like to experience a situation. He begins to describe a kind of "quality" that is sensed or felt in a situational context. He is quick to correct this use of words not to invite the impression of the situational quality being equivalent to a feeling, an emotion, or "anything mentalistic." He ventures on to say that, on the contrary, emotions, feelings and sensations themselves can only be described on account of the uniqueness of situations. His descriptions, of course, are not phenomenological in the sense of wanting to capture the essence of pure experience in isolation of any judgement. Rather, at this point his work becomes especially innovative, leaving behind traditional disciplinary boundaries, trying to convey an inseparability of a qualitative aspect of the situation's "controlling presence" and judgements at work, which never occur in isolation, but in relation to a kind of situational "implying" that Dewey is clear to distinguish from logical implication. The experienced situation's "regulating function" and its "pervasive and unifying quality," as in works of art, feed into distinctions that are relevant or coherent in relation 
to the situation (cf. Dewey 1938: 68f.; Dewey 1931). In the course of this process, distinctions evolve in interaction with the experienced situation, changing both, because a new description or solution, which emerges out of situational experience leads into a new situation.

At this point contemporary philosophers worry about a Deweyan lapse into givenism. This critique, as mentioned above, has recently been forwarded by Koopman, who warns that contemporary pragmatists who are eager to retrieve the classicopragmatist accounts of experience must be on guard to not treat experience as a kind of ultimate given-ness against which we might be able to measure our practical knowings, doings, and sharings (that is, our epistemic, ethical, and political practices) (Koopman 2009: 76f.).

Understanding Koopman's objection, we want to slow down at this point. If a situation were "there" in this manner as "something" regulating in a "given" way as a foundation for true distinctions, then Dewey's notion of situations would have to be dismissed as naive. Also, if his use of the term "quality of a situation" would imply something static, univocally there, something outside of the cognitive process, guaranteeing the adequacy of its representations, then Dewey's remarks concerning situations would instance givenism.

However, Dewey's notion of situations has to be grasped first and foremost in interactional terms. This will become more evident through Gendlin's approaches carrying Dewey's insistence on the function of situations even further. We understand Dewey's emphasis on a situational quality as an invitation to consider practice as necessarily rooted in body-environment interactions. It is no coincidence that he mentions the functions of a situation not only in his article on "Qualitative Thought," but also in his naturalistic account of logic.

50 While developing the rules and capacities of thought and language on the basis of bodyenvironment interaction as one integration, Dewey trains his readers not to consider both terms (body and environment) apart. ${ }^{5}$ He writes:

If what is designated by such terms as doubt, belief, idea, conception, is to have any objective meaning, to say nothing of public verifiability, it must be located and described as behavior in which organism and environment act together, or inter-act. (Dewey 1938: 33; original emphasis)

51 Let us suggest that experiencing a situation is enacting this integration and interaction on the complex level of human living and languaging (cf. Gendlin below). This allows us to consider situations as forms of interaction in which perceptions, beliefs, actions, meanings, contexts and environments are not given as separable elements, but as interdependent and interconnected. Whatever we single out in descriptions of situations, is a result of implicit or explicit differentiation-processes and of focused attention, with rich details playing important roles, which could open up to further details. The various degrees of subtlety in which we can talk about situations are decisive for individual or collective life. That the quality of a situation is not "given" like a perceivable quality, but is itself interaction, this is surprisingly to be found in Dewey's remarks on scholarly work. There he indicates different kinds of access to a challenging situation or problem, and he stresses a situation as a starting point of thinking that is primary, and more encompassing than any given observation and or conceptual framework at hand:

[...] it is more or less a commonplace that it is possible to carry on observations that amass facts tirelessly and yet the observed "facts" lead nowhere. On the other hand, it is possible to have the work of observation so controlled by conceptual 
framework fixed in advance that the very things which are genuinely decisive in the problem in hand and its solution, are completely overlooked. Everything is forced into the predetermined conceptual and theoretical scheme. The way, and the only way, to escape these two evils, is sensitivity to the quality of a situation as a whole. In ordinary language, a problem must be felt before it can be stated. If the unique quality of the situation is had immediately, then there is something that regulates the selection and the weighing of observed facts and their conceptual ordering. (Dewey 1938: 70) environment interaction that can be described in ever more subtle details, as well as in historical and social contexts, with first-person experience and feeling going along with this. Only in considering particular situational needs and challenges can differences in practice lead to progress and innovations. Situational experience consists of interactions that need to be specifically understood and met, not in static constituents and conditions. Dewey emphasizes:

Unless this fact is recognized, development becomes abnormal or at least unusual matter rather than a normal feature of life activities. Need remains a constant factor but it changes its quality. With change in need comes a change in exploratory and searching activities, and that change is followed by a changed fulfillment or satisfaction. Of human organisms it is especially true that activities carried on for satisfying needs so change the environment that new needs arise which demand still further change in the activities of the organism by which they are satisfied; and so on in a potentially endless chain. (Dewey 1938: 28)

55

Thus Dewey's Logic - A Theory of Inquiry ventures into a radical beginning of rationality in the organism's needful and productive relation to its environment as enacting an integration that maintains the living organism. The way things, and finally, categories become significant in living process cannot be sufficiently understood in representational terms, but by uncovering a situational-embodied dimension of need in which meaning is grounded in ways which are not given, hence, "needs" produce responses, actions, structures - and further interaction. Considering this embodied-behavioral dimension of meaning, Dewey becomes an acknowledged forerunner of the cognitive scientific turn to Embodiment (Crippen 2016). To become aware of this, he addresses his readers in an unusually direct manner by bringing awareness to a context that exceeds the text; a context that involves the living process of the reader. He indirectly demonstrates that it needs a different sort of concentration (practice!) to notice a situational background that is not identical to the conceptually trained focus. 
The reader, whether he agrees or not with what has been said, whether he understands it or not, has, as he reads the above passages, a uniquely qualified experienced situation, and his reflective understanding of what is said is controlled by the nature of that immediate situation. One cannot decline to have a situation for that is equivalent to having no experience, not even one of disagreement. (Dewey 1938: 69)

Dewey's invitation to direct attention away from the specific content to the "having" of a situation, manifests itself as a process of understanding, whether as an implicit agreement or disagreement. This is a bold shift within intellectual routine, or better, practice. It emphasizes a background of the cognitive process that is not in focus, but necessarily functioning for concepts and percepts to make contextual sense and meaning. However, this background is not a static given, but dynamic in character and requiring radical reflection in the course of conceptual thinking to become noticed (cf. also Schoeller/Saller 2016):

It would be a contradiction if I attempted to demonstrate by means of discourse, the existence of a universe of experience. It is not a contradiction by means of discourse to invite the reader to have for himself that kind of immediately experienced situation in which the presence of a situation as a universe of discourse is seen to be the encompassing and regulating condition of all discourse. (Dewey 1938: 69)

Claire Petitmengin's research on the emergence of ideas demonstrates that this kind of discursive invitation to notice implicit aspects of situational experiencing is a difficult, yet not impossible affair. Again, it requires practice and special methodologies developed for this purpose. Her elaborate interview techniques lead to surprising results that manifest in new, precise descriptions and distinctions of the emergent characteristics of the cognitive process. The transmodal quality of the descriptions of her interviewees blurs a rigid distinction between inner and outer, thus also undermining presumptions of "inner" and "outer sense" (cf. McDowell 1996: 22). Her thick descriptions of these subtle interactional processes even find applications in fields such as pedagogy and therapy (cf. Petitmengin 2007, Petitmengin 2016, Schoeller 2016).

In Dewey's understanding of situations, the philosophical picture of isolated subjects giving rise to the constant worry about the connection of human knowledge to the world, is left far behind. With Dewey we can think about how every epistemic move may prove to be clarifying or relevant, not by comparing it with a "given" immediate experience, but by experiencing the transformation of the situation, that has thus become possible. Arguments are not isolated propositions, but need to be understood in an environment of further arguments and counter-arguments, occasioning change, satisfying needs and developing novelties within the situational interaction. This can be deliberately cultivated in a responsive kind of cognitive practice, as we would like to demonstrate in this final part of the paper.

\section{Gendlin's Functional Relationships and Felt Sensing}

Rightly, one may ask why we include Gendlin in our choice of Classical Pragmatist authors. With the following section we want to indicate to what extent Gendlin, student of Dewey's student Richard McKeon, continues the Classical Pragmatist endeavor to think cognition and meaning in continuous terms of body-environment interaction (Gendlin 1997). His close-up study of the explicative process carefully explores and distinguishes 
the roles played by situational experience (Gendlin 1962). Gendlin's work allows us to trace the transformation of a situation by means of the subtle interaction of symbols and experienced situation, creating freshly nuanced meaning with every propositional transition. The Classical Pragmatist's emphasis on the particular situation gains new momentum with Gendlin, as the young philosopher is involved in Carl Roger's research consisting of the empirical study of the effect of therapy. Gendlin discovers very specific conditions of a transformative conceptualization of ordinary experience. His first book on Experiencing and the Creation of Meaning (Gendlin 1962) evolves from these interdisciplinary practices and perspectives. It integrates the vital functions of what he calls "experienced meaning" and later "felt sense" into his philosophical approach to language. His widened notion of feeling and emotion are today re-affirmed by cognitive scientists and philosophers (cf. Ratcliffe 2008, Damasio 1994).

In his field research, Gendlin notices that some people during a therapy session interrupt and pause the automated flow of speech, in order to attend and feel what they are trying to say.

61 His research proves that by attending to a felt meaning of situations and events, the semantic contents during therapies change in major shifts. These changes manifest in embodied-experiential ways, clarifying the actual issue, problem or situation with measurable release of tension. Gendlin writes: "Statements that speak-from the felt sense can be recognized by the fact that they have an effect on the felt sense. It moves, opens, and develops." (Gendlin 2004: 1; original emphasis). Feeling and articulating in this manner changes the felt quality of situations, in ways that a detached conceptual grasp, a narrative or an analytic understanding cannot provide (Gendlin 1961; 1964).

Gendlin's phenomenological close-up studies thus observe further functional aspects of the quality of a situation, which Dewey began to notice. A felt situation from which clients speak in sessions, shifts and responds to the way it is articulated. It is not a given foundation of propositional truths, yet the manifestation of an ongoing interaction of symbolization and situational living that requires attentiveness and responsive articulation, which can be practiced. The therapy-session thus becomes a magnifying glass on daily speech acts. While ordinary language philosophy emphasizes clear intentions as the condition of meaning, Gendlin shows how subject matters can develop, without clear intentional referents, yet in close felt relation to experienced messy and complex situations (Schoeller 2018a; 2018b). This explicative process consists in more than being able to follow logical and syntactical rules and speaking according to learned language games. Thus the explicative practice of a gradual clarifying content, which Gendlin analyzes, provides not only new approaches in therapy andthe philosophy of language, but also in neurophenomenological and cognitive research on creativity (Petitmengin 2007, Colombetti 2009, Schoeller 2017, Schoeller 2018a). In Classical Pragmatist spirit, Gendlin does not stay in the ivory tower of a philosophical discourse that is concerned only with the problems of philosophers, but dedicates his approach to the challenges of real life problems in transforming his findings into practices ("Focusing" and "Thinking at the Edge") which help to deal with the intricacy and complexity of modern day situations (cf. Gendlin 1981; 2004).

In Experiencing and the Creation of Meaning (1962), Gendlin conceptualizes the mutual transformative relation of symbols and "experienced meaning" as functional relationships. ${ }^{6}$ It is important to note here, that Gendlin's use of the word "functional relationship" is meant in a literal way. Taking Dewey's use of the word "function" a step 
further, Gendlin distinguishes seven well defined respects in which situational experience functions in language-use and vice versa. As one of the most basic features of these relations, Gendlin makes us aware of the remarkable fact that one does not have to choose between hundreds of words to say something in a situation.

The coming of words is so clever! They come specifically and newly phrased to make just your point! The words come with their past uses taken into account. Much that you have read and know is taken account of, as well as the present situation, what you just heard these people say, what you know of them from other times, even the peculiar way in which this group uses certain words. Why are words and situations inherently together in the bodily focaling that implies the right words? (Gendlin 1991: 104f.; original emphasis) allows a detailed account on cognition as a responsive transformational practice. Again, felt meaning or "felt sense" is not considered as "given" by Gendlin. In his main work A Process Model (2018a) he develops a notion of feeling as a dynamic, ever responsive product of a hyper-complex interaction process in which the body and different kinds of environments evolve and change together. different ways. In terms of philosophy of language, his close-up studies of the explication process are an important contribution in overcoming a representational as well as a constructive model of meaning. Gendlin's introduction of the technical term "carrying forward" (Gendlin 2004) opens up a new and phenomenological concise conceptualization of conceptuality in terms of process. When one is able to conceptualize what one thinks or feels, the formulation "carries" an experiential process "forward" as much as it specifies the meaning of the words one uses. What one says thus does not represent some 'given,' nor does it construct an (inner or outer) world. Formulating becomes a changeprocess on several interacting levels, yet not in an arbitrary way (Schoeller 2018a). Gendlin's term of "carrying forward" does justice to the difficulty we often encounter when Saying What We Mean (Gendlin 2018b, Schoeller 2017, Schoeller 2018a), and to the precision needed to formulate something in scientific, creative or daily contexts that makes a difference, by clarifying or transforming a situation, a problem, a thought or feeling. In terms of epistemology, Gendlin's thinking makes it necessary to face the challenge to think body-environment interaction, behavior, situations, culture and language together to grasp the challenge of meaning (Schoeller \& Dunaetz 2018). In this way, Gendlin needs to be counted to the pioneers of an embodied approach to meaning as early as the 1960ies, deeply disturbing conventional distinctions such as subject and object, body and mind, nature and culture, inside and outside etc. Gendlin does not only criticize a dualistic approach to the world, but delivers a robust alternative model of thinking (Gendlin 2018a, Schoeller 2018b). This introduces new basic distinctions which "carry forward" an understanding of meaning, while at the same time requiring a style or practice of thinking that becomes decisively more self-reflective.

Re-conceptualizing Dewey's term of situational implying (cf. Dewey 1931) as a precise, yet indeterminate need characterizing the body-environment interaction, Gendlin engages an "implying" that manifests in his own conceptual generating. He thereby develops an increasingly complex understanding of the phenomenon by radically reflecting each of his conceptual moves as always happening into an implicit context, each "occurring" (happening) "into an implying" that is thereby changed in intricate ways. He engages and unfolds this kind of continuity as the principle of emerging novelty, in which new 
possibilities of reflective process open up responsively to concepts, yet not determined by them (cf. Gendlin 1997).

Deriving the development of meaning on these grounds, Gendlin can gradually build conceptual tools that make conceivable how a situational feeling, and even slight changes in attending to it, can function in the coming of specific words attuned to the demands of the situation. The present situation becomes understandable as richly layered implicit process, in which a vast past is actively functioning. Feeling a situation, let alone speaking from it, becomes conceivable as a change-process that shifts in more ways than can be said simultaneously. Since each word is "a gigantic system of situation-changes and other words" (Gendlin 1991: 104f.), applying words is itself a crossing that creates new meaning, a term Gendlin introduces and which allows us to think beyond representational or constructivist models. The concept of crossing (Gendlin 1995), however, does not only apply to the use of language but to every occurrence: whatever happens interacts, that is, "crosses with" embodied situational living process, in which past occurrences function in forming the next event, regenerated and changed by the present. Therefore particular events include more implicit intricacy than we can propositionally spell out, and bodyexperiencing freshly exceeds what is conceptually differentiated. This also implies the necessity to philosophically cultivate a kind of attentiveness that expands the usual conceptual focus on propositions. Gendlin's methods "Focusing" and "Thinking-at-theEdge" exercise awareness for "what goes without saying" - for the subtly felt changes and shifts going on while articulating. Let us give a simple example. When seeing an inspiring film and speaking about it later on, the impact might easily shrivel away the more the analysis takes over. In other instances, however, the meaningfulness of the experience can grow and lead to further connections, clarifying, while we speak, the richly complex implications we felt. Gendlin suggests that these semantic differences result from a difference in explicative practice. Experiencing the impact of what we and others say, and speaking from that experience, adds another kind of precision to articulation; it provides situationally felt differentiations. If that happens, then we are glad we spoke. If, however, what we thought and experience shrivels while explicating, Gendlin has a simple piece of advice. He suggests pausing and sensing, “....." - and then have other words come from there:

We hope that the person will enter further into this “....., this edge, [...] When what wants to be spoken is only partly formed, if you can stand it as a ".....," then odd and quite newly formed phrases soon come from it. They develop it further, but not into something else, rather into something that follows from what you wanted to say and carries 'it' forward. (Gendlin 1999: 205)

\section{Conclusion}

Peirce's groundbreaking semiotic perspective opened up a new horizon for considering thought processes. The novelty of his approach consists in understanding that we "have no power of thinking without signs" (CP 2.265). Looking at the development from Peirce to Dewey, and then Gendlin, we have detected a coherent development of understanding knowledge as a transformational process, starting with iconic Firstness, through the having of situations, to the close interaction of situational experience and symbols. All three thinkers thereby also show that meaning extends beyond symbolic conceptualization. Peirce makes us aware that indeterminate or complex situational feelings, resemblances and occurrences must be considered as signs, as intrinsically 
relating to other characteristics, thoughts and objects. What endows meaning to things, as Terrence Deacon today reformulates, is always "an interpretive process" (Deacon 1997: 62), encompassing different sign levels and experiential stages. Conceptuality as understood in current debates is only one aspect of this process.

Dewey's notion of a situation exemplifies this point further. Although his situation appears to have little in common with a semiotic perspective at first sight, we suggest an underlying systematic continuity. The situation, characterized by Dewey as a feeling which functions in discourse, could be viewed in the Peircean spirit as a moment in the developing system of interconnected signs on different levels. However, Dewey contributes a further aspect, by emphasizing the importance of engaging the qualitative feeling of the situation as a subtle practice for gaining relevant distinctions.

In our opinion, this classical pragmatist approach goes further than "hopeful cultural criticism" (cf. Koopman 2009). Thinking closely from the predicaments of daily life and its challenges and conceiving thinking as a continuity that manifests in the precision of changed practice is more than hopeful criticism. It becomes life-changingly fruitful in methods that actually help to meet the demands of complex situations. This is what Gendlin demonstrates with his practices that are underpinned by his philosophy. His practices of Focusing and Thinking-at-the-Edge make the complex continuity of bodyenvironment-interaction, thought, feeling and symbol deliberately accessible, in daily life as well as in scientific and creative work (cf. Tokumaru 2011, Deloch 2010).

71 Although often neglected by mainstream academic philosophy, it is indisputable that the inspirational impact of the classical pragmatists' approach to knowledge not only overcomes traditional dualistic impasses of thinking, but opens up new avenues of theory, research and practice in many different fields outside of philosophy such as sociology, psychology, social anthropology and pedagogy. By conceiving knowledge as a transformative and interactional process, these thinkers demonstrate a dimension of experiential "firstness" that does not imply falling back into the Myth of the Given. Rather, by starting to spell out the complexity involved in conceptuality, they shift the challenges we need to consider: the intricacy of embodied and situated interactionalprocesses that functions in concepts which make sense, which are true or false, and which are performative in having the power to carry situations forward. Today, the paradigm of embodiment in cognitive science is acknowledged and proves congruent with their basic claims, showing how ahead of their times these thinkers were. In analytical philosophy, more and more classical pragmatist inspirations are re-integrated in order to deal with the epistemological problems of the Myth of the Given. Yet, the radical nature of Classical Pragmatist thinking of continuity on different levels is not yet tapped in its full potential. We trust that our study will inspire more detailed inquiry and commitment in pursuing this rich heritage for contemporary approaches to knowledge and meaning. On this note, we end with a quote from Peirce:

Thought must live and grow in incessant new and higher translations, or it proves itself not to be genuine thought. (CP 5.594) 


\section{BIBLIOGRAPHY}

BERMúdeZ José \& Arnon CAHEN, (2012), "Nonconceptual Mental Content," The Stanford Encyclopedia of Philosophy, Edward N. Zalta (ed.) [plato.stanford.edu/archives/spr2012/entries/contentnonconceptual/].

BRANDOM Robert B., (2011), Perspectives on Pragmatism, Cambridge, Harvard University Press.

colombetTi Giovanna, (2009), "What Language does to Feeling," Journal of Consciousness Studies, 16, $9,4-26$.

CRIPPEN Matthew, (2016), “Dewey, Enactivism and Greek Thought,” in Roman Madzia \& Matthias Jung (eds), Pragmatism and Embodied Cognitive Science: From Bodily Interaction to Symbolic Articulation, Berlin, De Gruyer, 229-46.

DAMASIO Antonio, (1994), Descartes' Error. Emotion, Reason, and The Human Brain, London, Penguin Books.

DAVIDSON Donald, (1974), “On the Very Idea of a Conceptual Scheme," in Id., Inquires Into Truth and Interpretation, Repr. Oxford, Clarendon, 1985.

DEACON Terrence, (1997), The Symbolic Species. The Co-evolution of Language and the Brain, New York, W. W. Norton \& Comp.

DELOCH Heinke, (2010), “Das Nicht-Sagbare als Quelle der Kreativität. E. T. Gendlins Philosophie des Impliziten und die Methode Thinking at the Edge (TAE)," in S. Tolksdorf \& H. Tetens (eds), In Sprachspiele verstrickt oder wie man der Fliege den Ausweg zeigt, Berlin, De Gruyter, 257-82.

DEWEY John, (1916), “The Pragmatism of Peirce,” The Journal of Philosophy, Psychology and Scientific Methods, 13 (26), 709-15.

DEWEY John, (1931), Qualitative Thought. Philosophy and Civilization, New York, Minton, Balch \& Comp, 93-116.

DEWEY John, (1938), Logic - The Theory of Inquiry, New York, Henry Holt and Co.

DREYFUS Hubert L., (2013), "The Myth of the Pervasiveness of the Mental," in J. Schear (ed.), Mind, Reason, and Being-in-the World. The McDowell-Dreyfus Debate, Oxon, OX, Routledge, 15-40.

EVANS Gareth, (1982), The Varieties of Reference, Oxford, Oxford University Press.

GENDLIN Eugene, (1961), "Experiencing: A Variable in the Process of Therapeutic Change,"

American Journal of Psychotherapy, 15 (2), 233-45.

GENDLIN Eugene, (1962), Experiencing and the Creation of Meaning: A Philosophical and Psychological Approach to the Subjective, Evanston, Northwestern University Press.

GENDLIN Eugene, (1964), "A Theory of Personality Change," in P. Worchel \& D. Byrne (eds), Personality Change, New York, John Wiley \& Sons, 100-48.

GENDLIN Eugene, (1981), Focusing, New York, Bantam Books.

GENDLIN Eugene, (1991), “Thinking Beyond Patterns: Body, Language and Situations," in B. den Ouden \& M. Moen (eds), The Presence of Feeling in Thought, New York, Peter Lang, 25-151. 
GENDLIN Eugene, (1995) “Crossing and Dipping: Some Terms for Approaching the Interface between Natural Understanding and Logical Formulation," Minds and Machines, 5, 4, 547-60. GENDLIN Eugene, (1997), “The Responsive Order: A New Empiricism,” Man and World, 30, 3, 383-411. GENDLIN Eugene, (1999), “Authenticity after postmodernism," Changes. An International Journal of Psychology and Psychotherapy, 17 (3), 203-12.

GENDLIN Eugene, (2004), "Introduction to Thinking at the Edge," The Folio, 19, 1.

GENDLIN Eugene, (2018a), A Process Model, Evanston, Northwestern University Press.

GENDLIN Eugene, (2018b), "Saying What We Mean. Implicit Precision and the Responsive Order," in Ed Casey \& Donata Schoeller (eds), Selected Works by Eugene T. Gendlin, Evanston, Northwestern University Press.

GoDfReY-SMITH Peter, (2010), "Dewey, Continuity, and McDowell," in D. MacArthur \& M. de Caro (eds), Normativity and Nature, New York, Columbia University Press, 304-21.

HANNA Robert, (2011), "Beyond the Myth of the Myth: A Kantian Theory of Non-Conceptual Content," International Journal of Philosophical Studies, 19 (3), 323-98.

JAMES William, (1904), "The Pragmatic Method," The Journal of Philosophy, Psychology and Scientific Methods, 1 (25).

JASTROW Joseph, (1916), “Charles S. Peirce as a Teacher," The Journal of Philosophy, Psychology, and Scientific Methods, XIII, 26, 723-26.

JUNG Matthias, (2009), Der bewusste Ausdruck. Anthropologie der Artikulation, Berlin, New York, De Gruyter.

KOOPMAN Colin, (2009), Pragmatism as Transition, New York, Columbia University Press.

LEVINE Stephen, (2012), "Norms and Habits: Brandom on the Sociality of Action," European Journal of Philosophy, 21 (2), 1-25.

MCDOWELL John, (1996), Mind and World, Cambridge, London, Harvard University Press.

MCDOWELL John, (2008), “Avoiding the Myth of the Given," in J. Lindgaard (ed.), John McDowell: Experience, Norm and Nature, Malden, MA, Oxford, UK, Carlton, Australia, Blackwell Publishing Ltd., 1-149.

PEACOCKE Christopher, (2001), "Phenomenology and Nonconceptual Content," Philosophy and Phenomenological Research, 62 (3), 609-15.

PEIRCE Charles S., (1931-1935), The Collected Papers of Charles Sanders Peirce I-VI, Ch. Hartshorne \& P. Weiss (eds), Cambridge, Harvard University Press.

PEIRCE Charles S., (1958), The Collected Papers of Charles Sanders Peirce VII-VIII. A. W. Burks (ed.), Cambridge, Harvard University Press.

PETITMENGIN Claire, (2007), "Towards the Source of Thoughts. The Gestural and Transmodal Dimension of Lived Experience," Journal of Consciousness Studies, 14, 3, 54-83.

PETITMEngin Claire, (2016). "The Scientist's Body at the Source of Meaning," in D. Schoeller \& V. Saller (eds), Thinking Thinking: Practicing Radical Reflection, Freiburg \& München, Verlag Karl Alber.

RANSDELl Joseph, (1979), “The Epistemic Function of Iconicity in Perception," in Peirce Studies. Studies in Peirce's Semiotic, Lubbock, Texas, Institute for Studies in Pragmaticism, 51-66. 
RATCLIFFE Matthew, (2008), Feelings of Being: Phenomenology, Psychiatry and the Sense of Reality, Oxford, Oxford University Press.

ROCKWELL W. Teed, (2005), Neither Brain nor Ghost, Cambridge, MIT.

SCHOELLER Donata, (2016), "Somatic - Semantic - Shifting: Articulating across the mind-body split," in Donata Schoeller \& Vera Saller (eds), Thinking Thinking: Practicing Radical Reflection, Frieburg \& Munich, Verlag Karl Alber.

SCHOELLER Donata, (2017), "Eternal Recurrence and the Limits of Critical Analysis," NietzscheStudien: Internationales Jahrbuch für die Nietzsche-Forschung, 46, 1, 153-66.

SCHOELLER Donata, (2018a), “Tentative Sprechakte: Zur erstaunlichen Entfaltbarkeit von Hintergründen beim Formulieren," Deutsche Zeitschrift für Philosophie, 66, 2, 183-201.

SCHOELLER Donata, (2018b), Close Talking. Erleben zur Sprache bringen, Berlin, De Gruyter.

SCHOELLER Donata \& Neil DUNAETZ, (2018), “Thinking Emergence as Interaffecting: Approaching and Contextualizing Eugene Gendlin's Process Model," Continental Philosophy Review, 51, 1, 123-40. To be reprinted in Mind and Matter, 16, 1 .

SCHOELlER Donata \& Vera SALLER (eds), (2016), Thinking Thinking: Practicing Radical Reflection, Frieburg \& Munich, Verlag Karl Alber.

schlicht Tobias, (2008), “Ein Stufenmodell der Intentionalität," in P. Spät (ed.), Zur Zukunft der Philosophie des Geistes, Paderborn, Mentis, 59-91.

SELLARS Wilfrid, (2000), "Empiricism and the Philosophy of Mind," in W. deVries \& T. Triplett (eds), Knowledge, Mind and the Given. Reading Wilfrid Sellar's "Empiricism and the Philosophy of Mind," including the complete text of Sellars's essay, Indianapolis, Hackett Publishing Company.

STERN Daniel, (1985), The Interpersonal World of the Infant. A View from Psychoanalysis and Developmental Psychology, New York, Basic Books.

TOKUMARU Satoko, (2011), Qualitative Research With TAE Steps: Thinking-at-the-Edge: Theory and Applications, Hiroshima, Keisuisha.

TSCHAEPE Marc Dietrich, (2013), "The Creative Moment of Scientific Apprehension: Understanding the Consummation of Scientific Explanation through Dewey and Peirce," European Journal of Pragmatism and American Philosophy 5 (1), 32-41 [journals.openedition.org/ejpap/578].

Viola Tullio, (2012), "Pragmatism, Bistable Images, and the Serpentine Line. A Chapter in the Prehistory of the Duck-Rabbit," in F. Engel, M. Queisner \& T. Viola (eds), Das bildnerische Denken: Charles S. Peirce, Berlin, Akademie Verlag, 115-38.

WELCHMAN Jennifer, (2008), "Dewey and McDowell on Naturalism, Values, and Second Nature," Journal of Speculative Philosophy, 22, 50-8.

ZAHAVI Dan, (2013), “The Myth of the Pervasiveness of the Mental," in Joseph K. Schear (ed.), Mind, Reason, and Being-in-the World. The McDowell-Dreyfus Debate, Abingdon, Oxon, New York, Routledge, 320-43.

\section{NOTES}

1. Cf. CP 5.183, and the commentary of Viola 2012. During his time as a lecturer at John Hopkins University Peirce worked together on experiments with Joseph Jastrow, who later on was the 
first who described the ambiguous picture of a duck-rabbit. The philosopher and the psychologist examined subliminal perception (cf. Jastrow 1916).

2. In his later works, he termed the accordance of meaning with truth - although only virtual potential - within his semiotic grid as the dynamic object.

3. We choose this unusual verb, inspired by the terminology of Aristotle (compare the following footnote) because we wanted avoid every possible idea of representation.

4. "Spoken words are symbols [symbola] of affections of the psyche; written words are symbols of spoken words. Like written words, spoken words are not the same for all persons. The affections of the psyche, however, of which these are primarily signs [semeia], are the same for all, as are also the objects [pragmata] of which the affections are likenesses [homoiomata]." De Interpretatione (16a3-7).

5. "The processes of living are enacted by the environment as truly as by the organism; for they are an integration." (Dewey 1938: 25; original emphasis).

6. He distinguishes between direct reference, recognition, explication, metaphor, comprehension, relevance, circumlocution.

\section{ABSTRACTS}

The paper elaborates the classical pragmatist understanding of cognition as a transformational process. The pragmatists' emphasis on the situatedness of cognition, on abductive moves and feeling will also be discussed in the light of the contemporary debate on conceptuality and givenism. Our inquiry on a classical pragmatist approach shifts today's emphasis on knowledge qua justification of belief and suggests ways to transcend the dualism of conceptuality vs. nonconceptuality. Reconsidering the Peircean category of Firstness, Dewey's quality of situations and Gendlin's felt sense as subtle tacit moments in cognitive processes enhance a fine-grained and contextualized understanding of cognition in terms of a transformative process.

\section{AUTHORS}

\section{VERA SALLER}

Psychoanalytical Seminar Zurich

vera.saller[at]hispeed.ch

DONATA SCHOELLER

Senior lecturer at Koblenz-Landau University and Programdirector at the Centre for Continuous Studies, University of Zurich

schoeller[at]uni-koblenz.de 